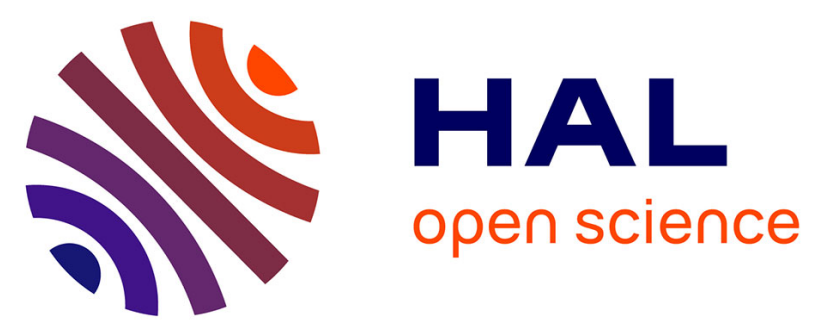

\title{
Characterization of behavior and cracking of a cement paste confined between spherical aggregate particles
}

Boleslaw Mielniczuk, Mouad Jebli, Frédéric Jamin, Moulay Saïd El Youssoufi, Céline Pelissou, Yann Monerie

\section{- To cite this version:}

Boleslaw Mielniczuk, Mouad Jebli, Frédéric Jamin, Moulay Saïd El Youssoufi, Céline Pelissou, et al.. Characterization of behavior and cracking of a cement paste confined between spherical aggregate particles. Cement and Concrete Research, 2016, 79, pp.235-242. 10.1016/j.cemconres.2015.09.016 . hal-01265589

\section{HAL Id: hal-01265589 \\ https://hal.science/hal-01265589}

Submitted on 1 Feb 2016

HAL is a multi-disciplinary open access archive for the deposit and dissemination of scientific research documents, whether they are published or not. The documents may come from teaching and research institutions in France or abroad, or from public or private research centers.
L'archive ouverte pluridisciplinaire HAL, est destinée au dépôt et à la diffusion de documents scientifiques de niveau recherche, publiés ou non, émanant des établissements d'enseignement et de recherche français ou étrangers, des laboratoires publics ou privés. 


\title{
Characterization of behavior and cracking of a cement paste confined between spherical aggregate particles
}

\author{
B. Mielniczuk ${ }^{\mathrm{a}, \mathrm{b}, \mathrm{c}, *}, \mathrm{M}$. Jebli ${ }^{\mathrm{b}, \mathrm{c}}$, F. Jamin ${ }^{\mathrm{b}, \mathrm{c}}$, M.S. El Youssoufi ${ }^{\mathrm{b}, \mathrm{c}}$, C. Pelissou ${ }^{\mathrm{a}, \mathrm{c}}$, Y. Monerie ${ }^{\mathrm{b}, \mathrm{c}}$ \\ a Institut de Radioprotection et de Sûreté Nucléaire IRSN, B.P. 3, 13115 Saint-Paul-lez-Durance Cedex, France \\ b LMGC UMR UM-CNRS 5508, University of Montpellier, 34095 Montpellier Cedex 5, France \\ c Laboratoire MIST, IRSN-CNRS-University of Montpellier, France
}

\begin{abstract}
In this work, the cement-grain interactions in a pair of $8 \mathrm{~mm}$ spherical grains of quartz or calcite, linked by a Portland cement, are analyzed experimentally at a local scale (cement-grain interface) during mechanical testing. The volume of the cement paste, the water/cement ratio and the gap between the grains are constant. Examined samples are conditioned in an atmosphere of constant temperature $\left(21^{\circ} \mathrm{C}\right)$ and high relative humidity ( $100 \%)$ to minimize drying shrinkage. At various stages of hydration, the samples are subjected to tensile or compressive tests, monitored by a high-speed camera. Stiffness and force at rupture are estimated and correlated to the crack initiation and propagation followed through image analysis. The results concern mechanical properties and kinetics of cracking in function of hydration time, for both types of loading and both types of grain. Such local characteristics will be used to propose local interaction laws and to support numerical modeling of the concrete at macroscopic scale.
\end{abstract}

\section{Introduction}

Concrete is a common component used in construction of buildings, roads, dams, bridges, but also in sensitive objects, as e.g. containment structures of nuclear power plants, where sustainability and stability must be ensured over long periods. The concrete is a granular and heterogeneous material, composed mainly of aggregates (coarse and fine) embedded in a matrix of cement paste (cement mixed with water), which fills the space between the aggregates and glues them together. This material reveals complex mechanical and physical behaviors, depending on its composition and its aging or conditions of its conservation. The concrete passes by a progressive structuration during reactions of hydration of cement, with change of its mechanical properties. Hydration of cement starts immediately after mixing cement with water, and may last during several tens of years [1]. Just after preparation, the concrete is elasto-plastic with pronounced ductility. When hardened, it has a good compressive strength but a low tensile strength and small range of deformation [2-4]. In result, it is very susceptible to cracking, which may have mechanical, physico-chemical or thermal origins. Cracking of the concrete affects significantly its durability, its mechanical parameters and its permeability [1-6]. Cracks in concrete are usually located at the cement-aggregate interface

* Corresponding author at: Institut de Radioprotection et de Sûreté Nucléaire IRSN, B.P. 3, 13115 Saint-Paul-lez-Durance Cedex, France.

E-mail address: boleslaw.mielniczuk@umontpellier.fr (B. Mielniczuk).
(Interfacial Transition Zone - ITZ), which is often weakened by its increased porosity [7-10]. In order to predict damage and fracture of concrete structures, the knowledge on cement-grain interface behavior has to be improved, with a detailed multi-scale analysis of conditions, origins and mechanisms of cracking. Since macroscopic properties of the concrete depend on their local characteristics, as e.g. physical properties of elementary components, structural composition and micro-geometry of the aggregate-cement interface or transport properties, it is necessary to examine concrete also at the local scale. Local characteristics of concrete and cement are widely described in literature (e.g. $[11,12]$ ), often accompanied by mechanical testing at the macroscopic scale, to exhibit relationships between microstructure and mechanical properties of concrete (e.g. $[13,14])$. To complete these analyses, mechanical tests at the local scale should be also introduced. By now, such tests have attracted only limited attention.

The purpose of this paper is to characterize the behavior and the fracture process of the cement interface at a local scale by experimental analysis of the aggregate-cement matrix interface at different stages of hydration. In particular, the determined mechanical parameters as stiffness $k(j)$ and force at rupture $f(j)$ are correlated with parameters of the kinetics of cracking: the speed of crack growth $v^{p}(j)$, the rate of crack opening $v^{o}(j)$, the angle $\beta$ between the crack and vertical axis of the sample and the tortuosity $\tau$, reconstructed basing on the analysis of high-speed camera images. Characterization of mechanical and physico-chemical interactions in cemented bond will contribute to this knowledge of concrete behavior. It will be also used to 
propose local interaction laws and to support numerical modeling at macro scale.

\section{Experiment}

In this study, mechanical behavior and cracking of cement interface linking two solid grains are examined at different stages of hydration. Examined samples consist in two identical quartz or calcite spherical grains, linked by a cement paste. Quartz and calcite are the main components of limestone (calcite) and sandstone (quartz) used usually as aggregates (sand, gravels) in concrete production [4].

Each grain has a cylindrical $1.3 \mathrm{~mm}$ hole perpendicular to the direction of traction (and compression), which allows to fix the sample during tensile testing. The cement paste is prepared using Portland cement and distilled water, with a water-cement ratio (W/C) of 0.5. The geometric configuration of the sample is shown in Fig. 1, while "material" data are given in Table 1 .

The samples are prepared using PVC molds, with constant gap between the grains and constant mass (and volume) of the cement paste. After preparation, samples are conditioned in stable and controlled atmosphere, with temperature of $21^{\circ} \mathrm{C}$ and high relative humidity $(\sim 100 \%)$. Such conditions limit the evaporation from boundary surfaces and therefore minimize the drying shrinkage. Samples are produced in series of about 10 each day, which gives a possibility to examine the samples at each stage of hydration, with several repetitions of each measurement.

Before mechanical testing, the PVC molds are removed and each sample is weighed and measured. At this stage, the samples which present some visible defects, as gaps, excessive deformation or initial cracking, are eliminated. This procedure allows to select only "well-done" samples to increase the quality and the repeatability of the results. Qualified samples are than fixed to the support of the MTS Universal Testing Machine M1/E [15], in order to carry out the mechanical tests (compressive and tensile testing).

Mechanical tests are realized mainly on early-age samples (from 1 to 28 days of hydration) at constant loading speed of $0.01 \mathrm{~mm} / \mathrm{s}$. During compression tests, the sample is placed between two plates, while during tensile testing the sample is fixed with pins inserted in the cylindrical holes (see Fig. 1b). For each test, the force-displacement curve is recorded using testwork4 software [15] and then post-processed using MS Excel and SciDAVis software [16]. Analysis of these curves allows to determine the peak force at rupture (maximal force) $f(j)$ and stiffness $k(j)$. The onset of cracking and rupture of the sample is recorded with use of a high-speed digital camera (Vision Research Phantom v12 [17]) at 40,000 frames per second. Obtained image sequences are treated using the ImageJ and MBRuler Pro softwares [18,19] in order to estimate the evolution of some geometrical parameters in function of hydration time $j$ and crack progression time $t$, such as sample diameter $d(z, t)$, crack opening $c(z, t)$, crack length $l_{T}(j), l_{p}(j)$ (see Fig. 1c) or angle $\beta$ between the crack and the vertical axis of the sample (Fig. 1c).

(a)

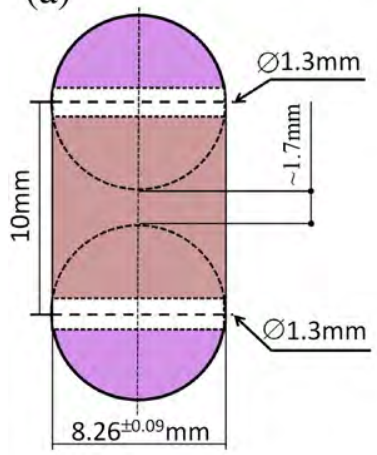

(b)

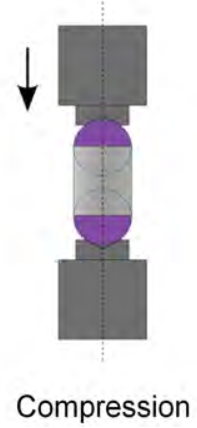

Table 1

Material data of used components.

\begin{tabular}{llll}
\hline Grains & \multicolumn{3}{c}{ Cement paste } \\
\hline Diameter of grains & $8.26 \pm 0.09 \mathrm{~mm}$ & Formula & CEM II/B-LL 32.5 N + \\
Calcite: formula & $\mathrm{CaCO}_{3}$ & & distilled water \\
Calcite: density & $2.6 \mathrm{~g} / \mathrm{cm}^{3}$ & W/C ratio & 0.5 \\
Quartz: formula & $\mathrm{SiO}_{2}$ & Mass & $0.5 \mathrm{~g} / \mathrm{sample}$ \\
Quartz: density & $2.65 \mathrm{~g} / \mathrm{cm}^{3}$ & Density (measured) & $2.22 \pm 0.22 \mathrm{~g} / \mathrm{cm}^{3}$ \\
\hline
\end{tabular}

These variables are used to reconstruct some parameters related to the kinetics of cracking, as time $t_{p}(j)$ at which the crack length is maximal, elapsed since the crack onset, the maximum of crack propagation speed $v^{p}(j)$ (Eq. (1)), the maximum of crack opening rate $v^{o}(j)$ (Eq. (2)) and crack tortuosity $\tau(j)$ (Eq. (3)).

$v^{p}(j)=\delta l_{T}(j) / \delta t$
$v^{o}(j)=\delta c(j) / \delta t$
$\tau(j)=l_{T}(j) / l_{p}(j)$

\section{Results}

Observations of the early-age samples before mechanical tests reveal that the apparent color of the surface, the volume fraction and the size of visible hydrates depend on the hydration time (see Fig. 2). Development of hydrates as function of hydration time is a wellknown result of chemical reactions of hydration, described widely by many authors [3-5].

\subsection{Compression tests}

For each compression test, force-displacement curves were recorded, as shown in Fig. 3. In general, one can observe a significant increase both of the maximal force $f_{C}(j)$ and of the stiffness of the samples $k_{C}(j)$ at the beginning of hydration. The stiffness $k_{C}(j)$ remains constant after about 10 days of hydration, while the maximal force $f_{C}(j)$ remains constant after more than 3 weeks of hydration.

A gentle decrease of the force after rupture is observed for the samples at very early-age. After several days of hydration, the samples become more brittle and a sudden force jump is observed just after the rupture (see Fig. 3). In general, the behavior of both types of samples is similar. Nevertheless, some differences are observed on forcedisplacement curves for early-age samples (first week) and they are not explained yet.

The evolution of maximum force $f_{C}(j)$ as a function of hydration time is presented in Fig. 4a, for both types of samples. The force at rupture $f_{C}(j)$ during compression tests is rather small at initial hydration stage

Fig. 1. Dimensions of the sample (a), supports for mechanical testing (b), and measured geometrical parameters (c).

(c)

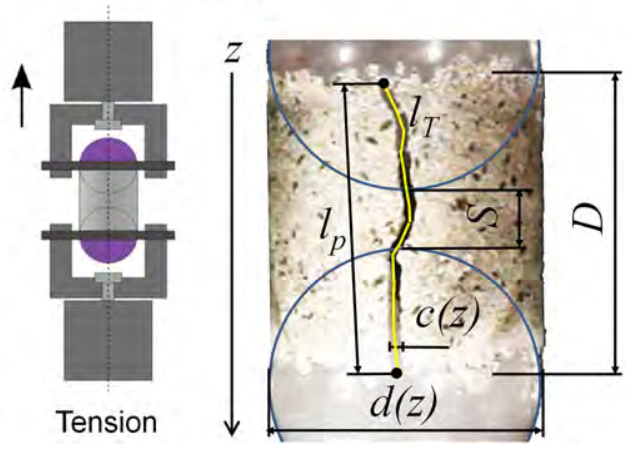



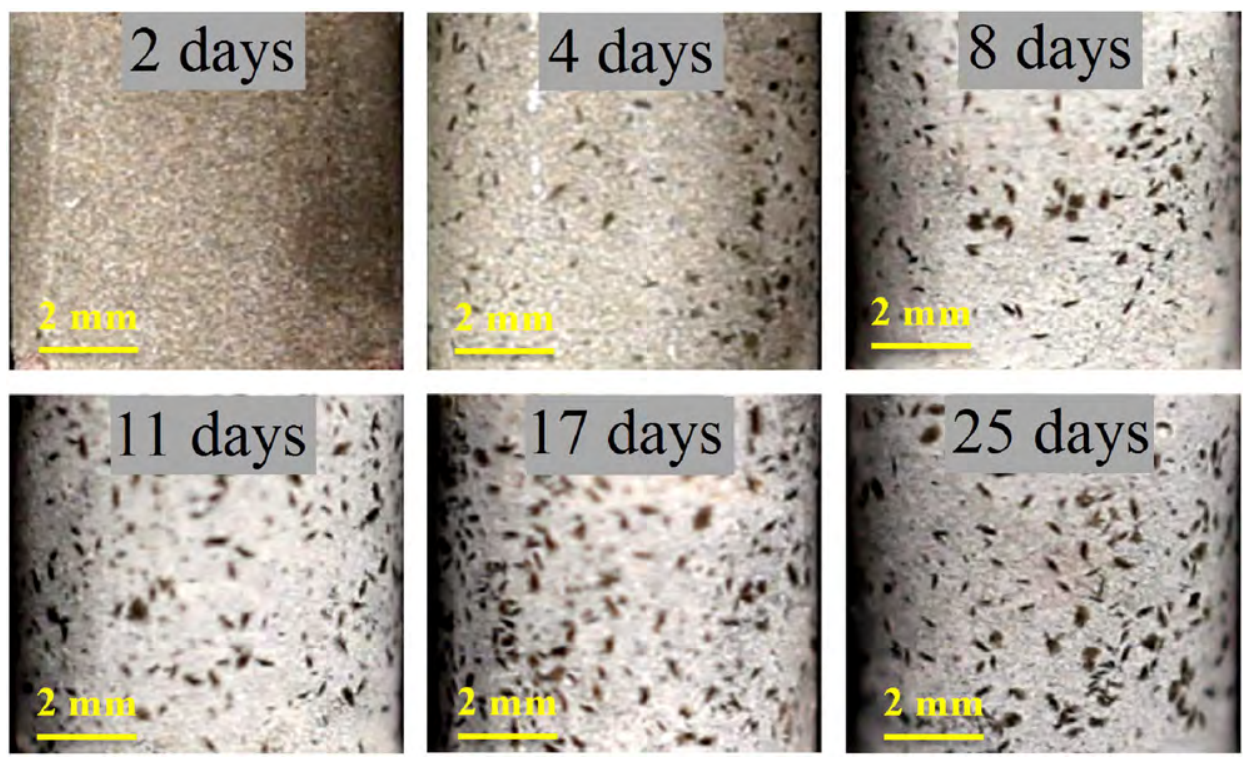

Fig. 2. Surface of samples at different stages of hydration (for different samples).

(about $100 \mathrm{~N}$ after 2 days of hydration), but it increases significantly after 4-5 days of hydration. Its evolution may be approximated by the exponential function, based on the equation (Eq. (4)) proposed in [20] in order to estimate the macroscopic compressive resistance of concrete.

$\left.f_{C}(j)=f \cdot \exp \left[A_{f} 1-\left(\frac{28}{j}\right)^{1 / 2}\right)\right]$

where $j$ is the hydration time (in days), $f$ is an approximative force after 28 days of hydration and $A_{f}$ is a mechanical parameter. The coefficients $f$ and $A_{f}$ of Eq. (4) are determined (fitted) based on obtained experimental results, with values of $f=1300 \mathrm{~N}$ for calcite, $f=1500 \mathrm{~N}$ for quartz, and $A_{f}=0.5$ for both types of samples.

The stiffness $k_{C}(j)$ of the samples was estimated from the slope of the linear part of force-displacement function. As expected, $k_{C}(j)$ also increases as a function of hydration time. A similar exponential function (Eq. (5)) can be used to approximate the evolution of the stiffness $k_{C}(j)$, as shown in Fig. $4 \mathrm{~b}$. Parameters $A_{k}$ and $k$ were determined also based on experimental results, with $k=8000 \mathrm{~N} / \mathrm{m}$ and $A_{k}=0.5$, for both types of samples.

$k_{C}(j)=k \cdot \exp \left[\begin{array}{ll}A_{k} & \left.\left.1-\left(\frac{28}{j}\right)^{1 / 2}\right)\right]\end{array}\right.$

where $k$ is an approximative stiffness after 28 days of hydration and $A_{k}$ is a mechanical parameter.

Comparing obtained figures (Figs. 3, 4) with macroscopic results of compression test, it may be concluded, that the evolution of mechanical parameters during compressive testing of examined samples resembles strongly the evolution of resistance and stiffness of macroscopic concrete samples, although its dimensions and compositions are different (see i.e. [21-23]).

\subsection{Tensile tests}

Tensile tests on concrete are difficult to achieve and exhibit often strongly scattered results [24]. Several types of tensile tests are used at the macroscopic scale, i.e. direct tensile test, Brazilian-like tests or
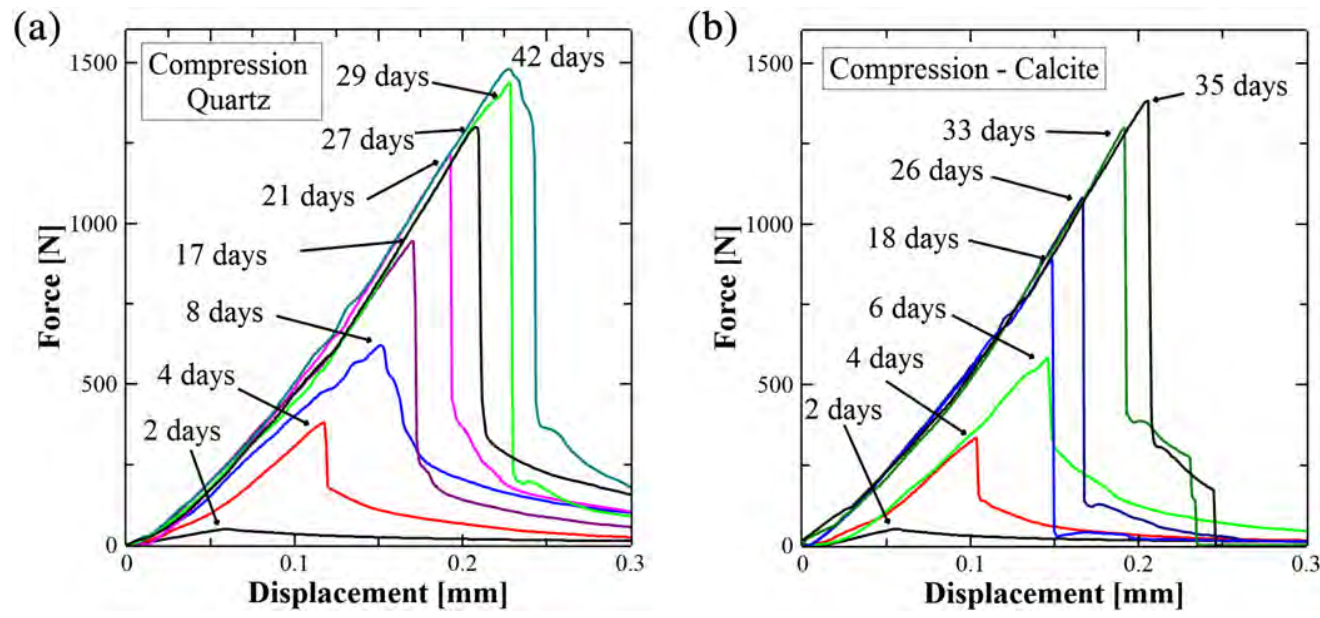

Fig. 3. Force-displacement curves during compression tests with grains of quartz (a) and calcite (b) for different times of hydration. 

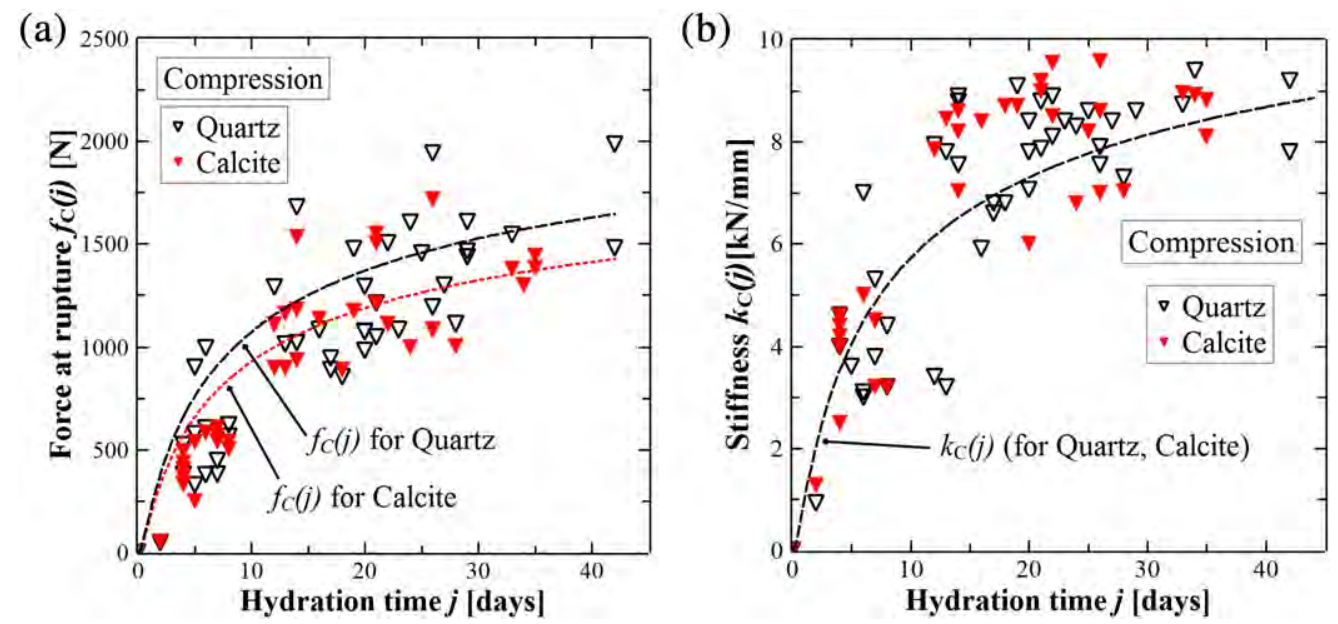

Fig. 4. Evolution of the maximum force (a) and of the stiffness (b) as a function of hydration time during compression tests for samples with grains of quartz and calcite.

three-point bending tests. Tensile testing of concrete at a local scale is however less investigated.

In this study, direct tensile tests are performed on the samples consisted of two grains, bounded by a cement paste. The principle of these tests is quite simple, but the tests have to be conducted very carefully in particular to avoid mis-alignment of the support and thus to minimize tilt or bending. Moreover, other parameters are difficult to control and can strongly influence the overall tensile response, e.g. the heterogeneity of the paste, the presence of air pockets, micro-cracks or a higher porosity in the cement-aggregate interface.

During tensile tests, the examined sample is fixed with pins placed in the holes of the grains (Fig. 1b) and extended with constant speed of $0.01 \mathrm{~mm} / \mathrm{s}$, with continuous recording of force-displacement curves. The curves recorded for both types of sample at different stage of hydration are presented in Fig. 5. For both types of grain, maximum force $f_{T}(j)$ and stiffness $k_{T}(j)$ increase with hydration time, with slightly higher values for the samples with grains of quartz. Such dependence was observed also during compressive tension, but all corresponding values are much lower than during compression tests. In addition, the ductile behavior was not observed during tensile testing, neither for very young samples. For tensile tests, force as a function of displacement goes very rapidly to zero at the moment of the rupture, just after reaching its maximum (Fig. 5).

The evolution of the maximal force $f_{T}(j)$ during tensile tests is presented in Fig. 6a. The experimental data are approximated using a direct relationship between the maximal tensile force $f_{T}(j)$ and maximal compressive force $f_{C}(j)$, as noted in Eq. (6). Similar type of equation is

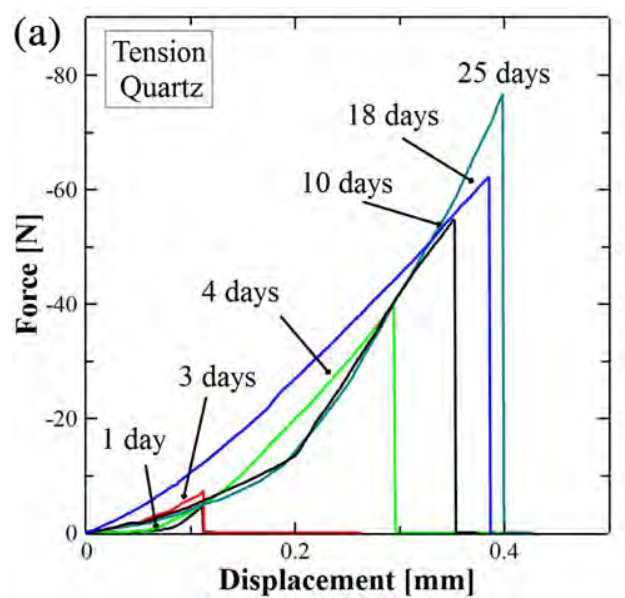

proposed in [25] to estimate tensile resistance in function of compressive resistance during macroscopic tests of concrete.

$f_{T}(j)=0.05 \cdot f_{C}(j)$

The curves obtained during tensile tests are qualitatively comparable for both types of grain. Eq. (6) shows in particular that the maximal tensile force $f_{T}(j)$ is about 15 times larger than the compressive one, with maximal $f_{T}(j) \sim 100 \mathrm{~N}$ for hardened samples and maximal $f_{C}(j) \sim 1500-2000 \mathrm{~N}$.

The evolution of the tensile stiffness $k_{T}(j)$ is shown in Fig. 6b. Again, the compressive stiffness $k_{C}(j)$ may be linked to the tensile one (Eq. (7)). The compressive stiffness $k_{C}(j)$ is about 20 times larger than the tensile stiffness $k_{T}(j)$ (the maximal $k_{T}(j) \sim 450 \mathrm{~N} / \mathrm{mm}$, the maximal $\left.k_{C}(j) \sim 9000 \mathrm{~N} / \mathrm{mm}\right)$.

$$
k_{T}(j)=0.05 \cdot k_{C}(j)
$$

Comparing the evolution of mechanical parameters during tensile testing at local scale (Figs. 5, 6) with similar results for macroscopic samples, it may be concluded, that behavior of samples differs, depending on the scale. For macroscopic samples, ductile part of strain-stress curve may be distinguished, where propagation of fissures takes place $[22,23]$. At local scale, there is only one observed fissure, which propagates very fast across the cement-grain interface (rupture in about $1 \mathrm{~ms}$ ). In this case, a sudden decrease (jump) of tensile force is observed, with no trace of ductile behavior (Fig. 5).

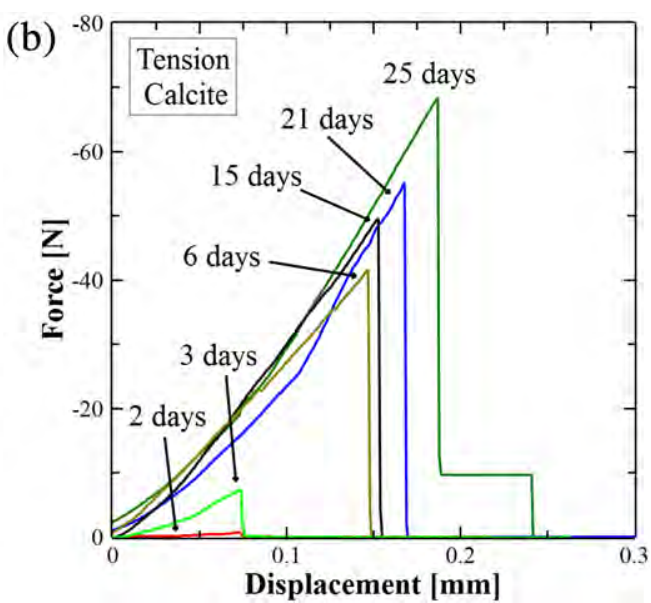

Fig. 5. Evolution of the force vs displacement during tensile tests on samples with grains of quartz (a), and calcite (b). 

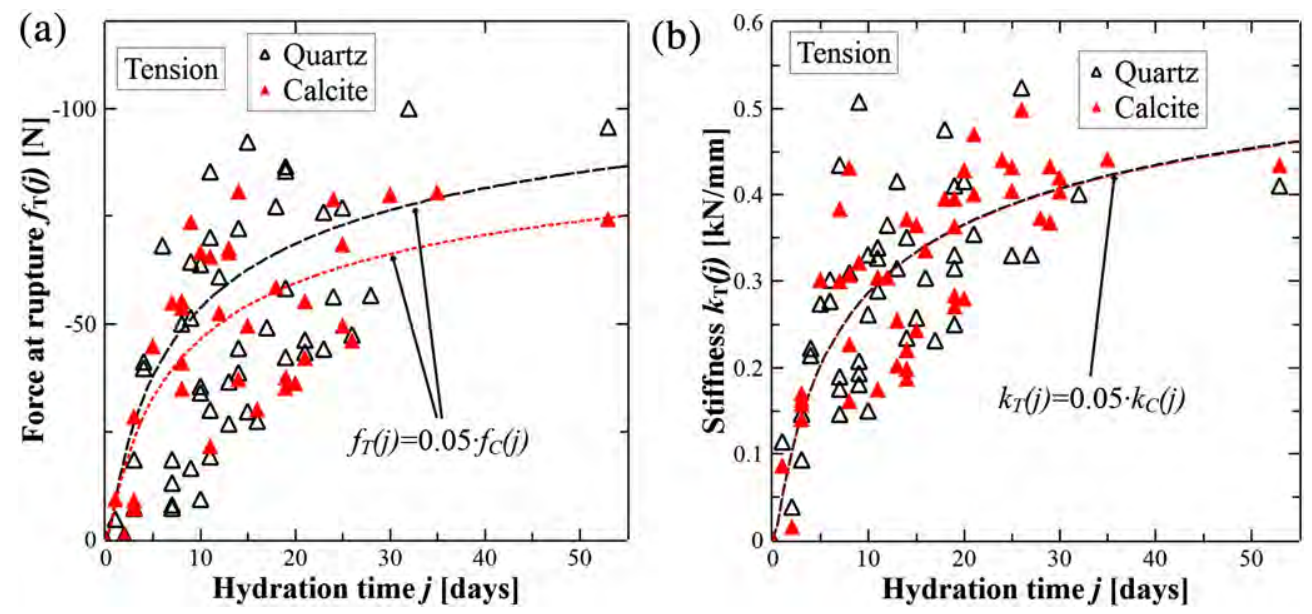

Fig. 6. Evolution of force at rupture (maximum force) (a) and stiffness (b) in function of hydration time during tensile tests for samples with grains of quartz and calcite.

Assuming after Fig. 3 and 5 a quasi-brittle behavior in compression and in tension for both types of sample, we focus in the sequel our attention on an effective upper bound of the critical energy release rate as a function of the hydration time:

$G_{c}(j)=\frac{1}{2} \frac{f_{C}^{2}(j)}{k_{C}(j)}$ in compression, $G_{c}(j)=\frac{1}{2} \frac{f_{T}^{2}(j)}{k_{T}(j)}$ in tension

where $f_{C}(j)$ and $f_{T}(j)$ are given by Eqs. (4) and (6) respectively and $k_{C}(j)$ and $k_{T}(j)$ are given by Eqs. (5) and (7) respectively. Fig. 7 shows that this quasi-brittle estimate well approximates the experimental data. The compressive and tensive toughnesses of the tested samples clearly increase with respect to the hydration time and reach progressively a quite stabilized value. Again, the toughness of the samples with grains of quartz is larger than the one the samples with grains of calcite.

\section{Crack tracking}

During all mechanical tests, image sequences are recorded at high frequency (about 40,000 frames per second), in order to observe crack propagation (Fig. 8). Then the part containing progress of cracking and the rupture was extracted from obtained sequences of images. Based on these sequences, the evolution of different variables was determined as a function of the progression of cracking time $t$ and the hydration time $j$, as the total time of cracking $t_{p}$, the maximum and the average of the crack speed $v^{p}(j)$, the rate of crack opening $v^{o}(j)$, the angle $\beta(j)$ between the crack and vertical axis of the sample and the tortuosity $\tau$.

\subsection{Crack direction and tortuosity}

The first characteristic, which was observed immediately during testing, is the direction of the crack propagation. During compressive tests, the cracks initiate and propagate always along the vertical direction (Fig. 8a), while during tensile tests the rupture of the samples occurs systematically at the cement-grain interface, with a propagation along the horizontal direction (Fig. 8b). To quantify the direction of cracking, the angle $\beta$ between the direction of crack and the vertical axis of sample was measured for each test. The measured angles $\beta$ are thus splitted into two groups. The mean angle between the crack and the vertical axis of the sample is $\beta \sim 90^{\circ}$ for the tensile tests (vertical cracks) and $\beta \sim 1.5^{\circ}$ for the compression tests (horizontal cracks), without any significant variation with time of hydration $j$ (see Fig. 9a and Table 3).

The tortuosity of cracks $\tau$ (Eq. (3)) was determined for each sequence. Its mean value is presented in Fig. $9 \mathrm{~b}$ and in Table 3. There is no clear relationship between tortuosity $\tau$, hydration time $j$ and the type of examined grains.
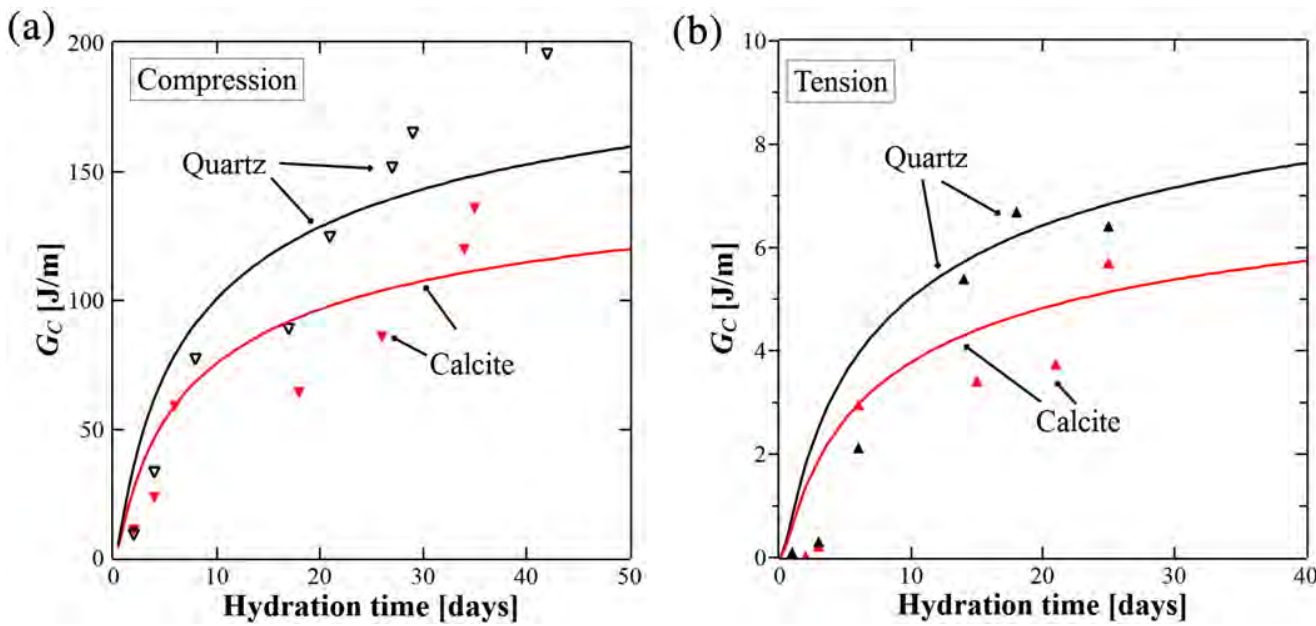

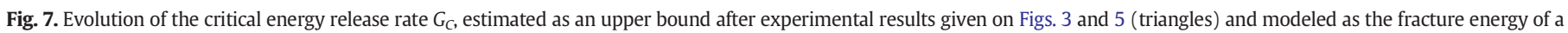
quasi-brittle material with Eqs. (4) and (5) (solid lines) during compressive (a) and tensile (b) tests on samples with grains of quartz and calcite. 

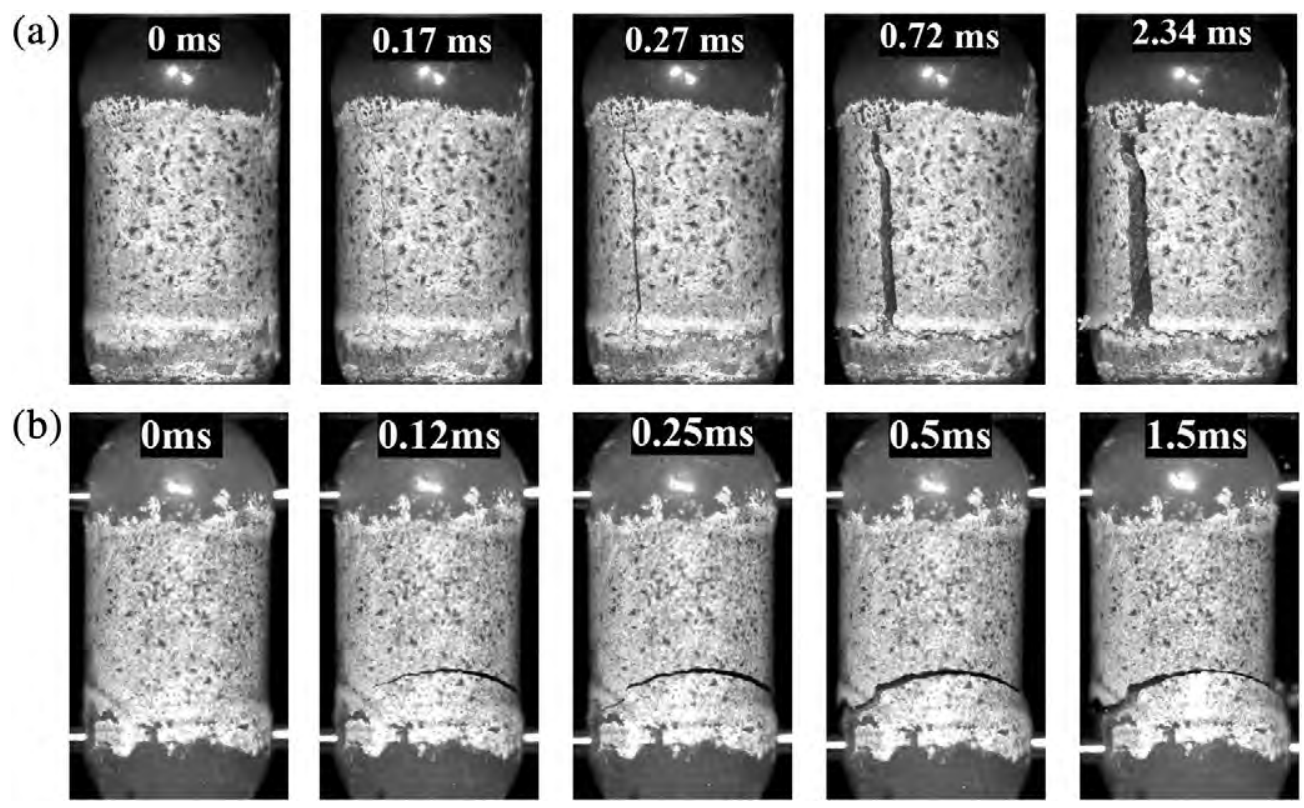

Fig. 8. Crack growth in cement paste between grains of quartz during: compression (23 days of hydration) (a) and tension (21 days of hydration) (b).

\subsection{Crack speed}

Obtained sequences of images were also used to estimate the kinetics of cracking during both tests. Kinetics of cracking may be quantified by the maximum of the crack speed $v^{p}(j)$ (Eq. (1)) and the maximum of the crack opening rate $v^{o}(j)$ (Eq. (2)). The evolution of these parameters with the hydration time $j$ for both tests is shown in Fig. 10. The speed of crack propagation $v^{p}(j)$ and crack opening rate $v^{o}(j)$ remain quite small for the samples tested during the first days of hydration, but these quantities increase with the hydration time. Such behavior is consistent with the embrittlement associated to the progress of hydration: with increase of hydration time samples become harder and more resistant, but also more fragile (see i.e. Fig. 4). In general, propagation of cracks from the onset to its maximum length lasts only about $1 \mathrm{~ms}$ for all samples after 3 days of hydration. Moreover, we underline that the results given in Fig. 10 do not exhibit any significant dynamic propagation.

For both types of tests, experimental results were approximated using two types of equations. For tensile tests, crack propagation speed and crack opening rate may be approximated using exponential equation (Eqs. (9), (10)) similar to equations using for approximation curves of $f_{C}(j)$ (Eq. (4)) and $k_{C}(j)$ (Eq. (5)).

$\left.v_{T}^{p}(j)=a_{T} \cdot \exp \left[0.61-\left(\frac{28}{j}\right)^{1 / 2}\right)\right]$

$\left.v_{T}^{o}(j)=b_{T} \cdot \exp \left[0.51-\left(\frac{28}{j}\right)^{1 / 2}\right)\right]$

Parameters $a_{T}$ and $b_{T}$ were fitted on obtained experimental results, with values presented in Table 2 .

For compression tests the relation between kinetic parameters and hydration time may be given by a linear function (Eqs. (11), (12)), with slopes of both functions $a_{C}$ and $b_{C}$ are presented in Table 2 for both types of samples.

$v_{C}^{p}(j)=a_{C} \cdot j$
$v_{C}^{o}(j)=b_{C} \cdot j$

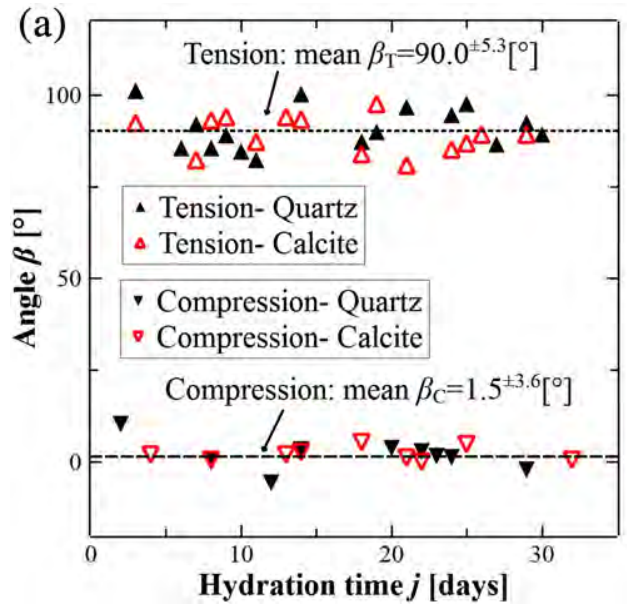

(b)
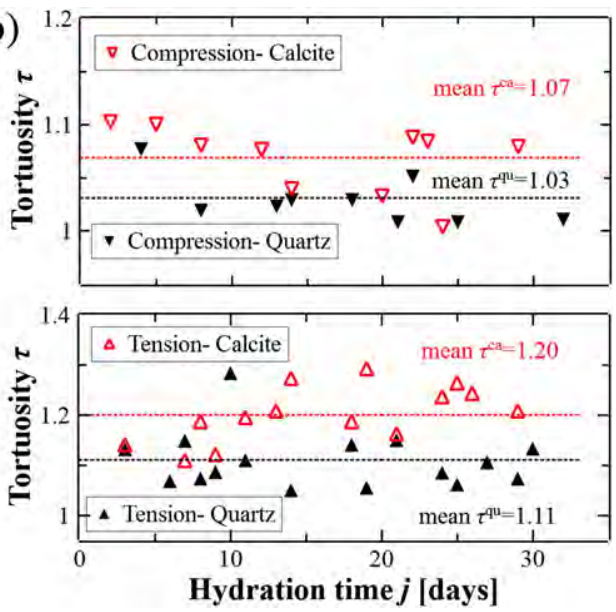

Fig. 9. Evolution of angle $\beta$ between the crack and vertical axis of the sample (a) and tortuosity $\tau$ (b) as a function of hydration time. 
Table 2

Parameters $a_{T}, b_{T}$ and $a_{C}$ and $b_{C}$ used to approximate the maximum crack progression speed $v^{p}(j)$ and the maximum crack opening speed $v^{o}(j)$ for both types of samples.

\begin{tabular}{lllll}
\hline & $a_{T}[\mathrm{~m} / \mathrm{s}]$ & $b_{T}[\mathrm{~m} / \mathrm{s}]$ & $a_{C}\left[\mathrm{~m} / \mathrm{day}^{2}\right]$ & $b_{C}\left[\mathrm{~m} / \mathrm{day}^{2}\right]$ \\
\hline Calcite & 190 & 2.88 & 3.6 & 0.035 \\
Quartz & 150 & 3.12 & 2 & 0.023 \\
\hline
\end{tabular}

Table 3

Comparison of crack parameters on all hydration time: the maximum of speed of propagation $v^{p}(j)$, the maximum of the crack opening rate $v^{o}(j)$, mean cracking time $t_{p}$ mean angle $\beta$ and tortuosity $\tau$, obtained for each type of tests.

\begin{tabular}{lcccccc}
\hline & Quartz & & & \multicolumn{2}{l}{ Calcite } & \\
\cline { 2 - 3 } & Tension & Compression & & Tension & Compression \\
\hline Maximum $v^{p}(j)[\mathrm{m} / \mathrm{s}]$ & 198 & 86.2 & & 219 & 111 \\
Maximum $v^{\circ}(j)[\mathrm{m} / \mathrm{s}]$ & 4.32 & 0.73 & & 3.35 & 1.18 \\
Mean time $t_{p}[\mathrm{~ms}]$ & 0.44 & 1.55 & & 0.27 & 0.87 \\
Mean angle $\beta\left[^{\circ}\right]$ & 90.74 & 1.33 & & 89.13 & 1.73 \\
Mean tortuosity $\tau[-]$ & 1.11 & 1.03 & & 1.20 & 1.07 \\
\hline
\end{tabular}

The summary of reconstructed parameters for all test types is presented in Table 2. Kinetics of cracking is visibly higher for tensile tests, with higher the maximum of progression speed and higher the maximum of opening rate. The maximum total time of crack propagation is visibly lower for tensile tests.

\section{Conclusions}

In this paper, first results of the study on local behavior of a cemented bond during mechanical tests are presented. Obtained results refer to evolution of force and stiffness during mechanical testing, and to progression of cracking and rupture of cemented grains. Presently, the results are presented mainly from a qualitative point of view, to describe and compare characteristics of cement-grain interface behavior. It is observed that both, maximal force (force at rupture) $f(j)$ and stiffness $k(j)$ increase with the time of hydration during compression and tensile testing. Values of both parameters are quantitatively similar for grains of quartz and of calcite, and much higher during compression tests. The evolution of these parameters is well approximated by an exponential function (Eqs. (4), (5), (6), (7)) [4,5]. This type of equation is commonly used to estimate the macroscopic resistance of the concrete. In this study, it is used as an initial estimation of the evolution of mechanical parameters in function of hydration time.

The maximal force at compressive testing $f_{C}(j)$ is more than 10 times higher than the maximal force at tensile testing $f_{T}(j)$, with linear relation found between these two parameters (Eq. (6)). Similar relation may be used to approximate the evolution of the stiffness at tension $k_{T}(j)$, as a linear function of the stiffness at compression $k_{C}(j)$ (Eq. (7)).

The kinetics of cracking is strongly dependent on the type of test and on hydration time (Fig. 10), but it is only slightly dependent on type of grains used to prepare the sample. The speed of crack progression $v^{p}(j)$, as well as crack opening rate $v^{o}(j)$, are much higher for tensile tests than compressive tests. Such behavior is related to the mechanical behavior during both tests, where ductile rupture is observed during compression (at early age), but only brittle rupture during tensile testing (Figs. 3, 5). The direction of cracks depends also on the type of test, with vertical cracking at compression, and horizontal at tension (Figs. 8, 9a). One can also note the important role of the interfacial transition zone ITZ at tensile testing, when rupture occurs always at the grain-cement interface. Such behavior confirms the increased fragility of this zone.

Results obtained during several series of tests are quite encouraging. With use of image analysis techniques, it is possible to quantify the cracking of concrete in a very local scale of cement-aggregate interface.

We confirmed the dependence between mechanical properties, dynamics of cracking and time of hydration, well-known in macroscale examinations of concrete $[4,26]$. Mechanical tests and analysis of rupture of cement bond between grains are not frequent and are not thoroughly investigated. In performed experiments, it was necessary to create and adjust all stages of experimental protocol, from sample preparation, through construction of supports, to image treatment and data post-processing. To improve the concrete characterization, to increase repeatability and to have access to some additional parameters, several improvements of the experimental protocol have been proposed, concerning sample preparation, sample geometry, conditioning, other types of tests and image treatment techniques.

To minimize the influence of chemical and drying shrinkage (eliminate evaporation, assure continuous water supply), samples could be immersed and conditioned in water after $24 \mathrm{~h}$ of conditioning in high relative humidity. Initial results of tests performed on such conditioned samples show the increase of maximum strength and lower dispersion of results (see [27]). The use of other form and geometry of sample, i.e. cylindrical or rectangular grains with different surface roughness, could allow to estimate stress development and determine the influence of the interface on mechanical properties of cemented grains.

To complete the results, bending and shear tests are planned, as well as mechanical tests on hardened samples, beyond 28 days of hydration. Additional tests will facilitate the interpretation of the results, with possibility of quantifying additional variables, currently inaccessible, as
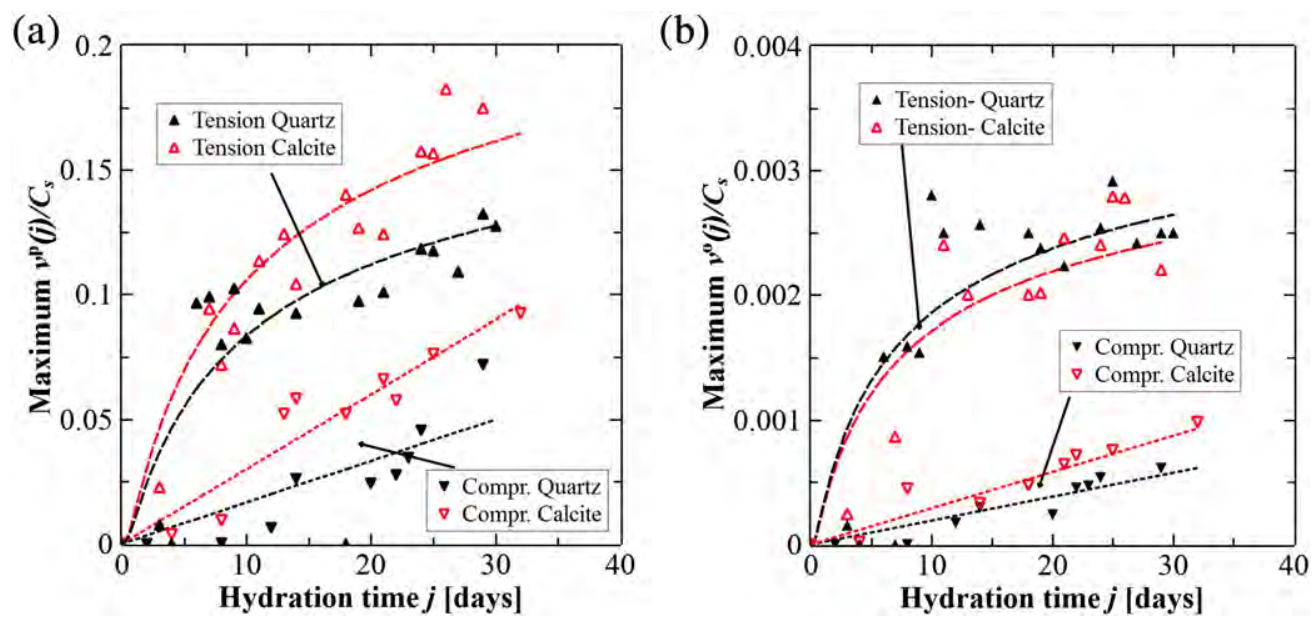

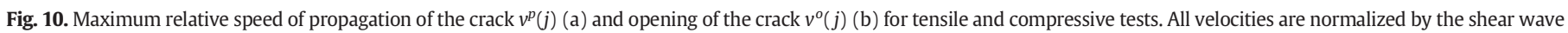
speed in compression of the cement paste $C_{s}$ (estimated here as about $1200 \mathrm{~m} / \mathrm{s}$ ). 
e.g. stress, strength, Young's modulus of sample and cracking energy for each stage of hydration. To accelerate and increase the accuracy of image treatment, advanced image correlation techniques will be used $[28,29]$, which will allow to examine more samples, and improve statistical analysis. The characterization of the mechanical and physicochemical interactions in cemented bond will serve in the longer term to determine local interaction laws, which will be used in numerical modeling and simulations in macroscopic scale, scale of Representative Elementary Volume (REV). These studies should contribute to the understanding of concrete behavior and the development of tools to predict, anticipate and avoid fracturing and damage of concrete structures.

\section{References}

[1] G. Tattersall, P. Banfill, The Rheology of Fresh Concrete, Pitman Advanced Publishing Program, 1983.

[2] O.J. Baron, J. Huang, Les bétons: bases et données pour leur formulation, Construction béton, Eyrolles, 1997.

[3] A. Neville, Propriétés des bétons, Eyrolles, 2000.

[4] F. Lea, P. Hewlett, Lea's Chemistry of Cement and Concrete, Elsevier ButterworthHeinemann, 2004.

[5] H. Taylor, Cement Chemistry, Thomas Telford, 1997.

[6] F. Perche, Adsorption de polycarboxylates et de lignosulfonates sur poudre modele et cimentsPh.D. thesis STI, Lausanne, 2004.

[7] S. Diamond, Considerations in image analysis as applied to investigations of the ITZ in concrete, Cem. Concr. Compos. 23 (2-3) (2001) 171-178.

[8] S. Diamond, J. Huang, The ITZ in concrete-a different view based on image analysis and SEM observations, Cem. Concr. Compos. 23 (2-3) (2001) 179-188.

[9] E. Schlangen, J.V. Mier, Experimental and numerical analysis of micromechanisms of fracture of cement-based composites, Cem. Concr. Compos. 14 (2) (1992) 105-118 (Special Issue on Micromechanics of Failure in Cementitious Composites).

[10] T.D. Nguyen, Study of the interfacial transition zone "porous limestone aggregates-cement paste": influence of physico-mechanical properties of aggregates; consequence on the mechanical properties of mortarPh.D. thesis Ecole Nationale Supérieure des Mines de Saint-Etienne, 2013.
[11] Y. Gao, G.D. Schutter, G. Ye, H. Huang, Z. Tan, K. Wu, Porosity characterization of ITZ in cementitious composites: concentric expansion and overflow criterion, Constr. Build. Mater. 38 (2013) 1051-1057.

[12] S. Diamond, The microstructure of cement paste and concrete-a visual primer Cem. Concr. Compos. 26 (8) (2004) 919-933.

[13] P.R. Rangaraju, J. Olek, S. Diamond, An investigation into the influence of inter-aggregate spacing and the extent of the ITZ on properties of Portland cement concretes, Cem. Concr. Res. 40 (11) (2010) 1601-1608.

[14] O. Buzzi, M. Boulon, M. Hervé, K. Su, Leaching of rock-concrete interfaces, Rock Mech. Rock. Eng. 41 (3) (2008) 445-466.

[15] MTS Systems Corporation, URL http://www.mts.com/ 2002.

[16] Scientific Data Analysis and Visualization SoftwareURL http://scidavis. sourceforge.net/ 2014.

[17] Vision Research, Phantom v12, URL http://www.visionresearch.com/ 2011.

[18] W. Rasband, Image processing and analysis in JavaURL http://rsb.info.nih. gov/ij/ 2014.

[19] M. Bader, MBRuler Pro, URL http://www.markus-bader.de/MB-RulerPro/ 2012.

[20] European Committee for Standardization, EN 1992-1-2:2004 Eurocode 2: Design of Concrete Structures, CEN, 2004.

[21] J. Van Mier, Strain-softening of Concrete under Multiaxial Loading Conditions, Technische Hogeschool Eindhoven, 1984.

[22] M. Arnould, M. Virlogeux, Granulats et bétons légers - bilan de 10 ans de recherche, Presses de l'École Nationale des Ponts et Chaussées, 1986.

[23] J. Torrenti, Propriétés des bétons, Hermés, 2002.

[24] M. Saito, Characteristics of microcracking in concrete under static and repeated tensile loading, Cem. Concr. Res. 17 (2) (1987) 211-218

[25] BAEL: Règles techniques de conception et de calcul des ouvrages et construction en béton armé suivant la méthode des états limites, Eyrolles, 2001.

[26] Z.P. Bazant, Mechanics of distributed cracking, Appl. Mech. Rev. 39 (5) (1986) 675-705.

[27] M. Jebli, B. Mielniczuk, F. Jamin, C. Pelissou, M.S. El Youssoufi, Etude expérimentale de la lixiviation du béton á l'échelle de l'interface pâte de ciment-granulats, AUGC 15, Bayonne, 27-29 mai, 2015.

[28] B. Wattrisse, A. Chrysochoos, J.-M. Muracciole, M. Némoz-Gaillard, Analysis of strain localization during tensile tests by digital image correlation, Exp. Mech. 41 (1) (2001) 29-39.

[29] J. Valença, D.D. da Costa, E. Júlio, Characterisation of concrete cracking during laboratorial tests using image processing, Constr. Build. Mater. 28 (1) (2012) 607-615. 